\title{
Map use in lessons: a videostudy findings
}

\author{
Kristyna Stolcova $^{a}$ *, Martin Hanus ${ }^{b}$ \\ ${ }^{a}$ Charles University, Prague, Faculty of Science, stolcovk@natur.cuni.cz \\ ${ }^{b}$ Charles University, Prague, Faculty of Science, martin.hanus@natur.cuni.cz. \\ * Corresponding author
}

Keywords: Cartographic skills, maps, education, teaching styles, map use

\begin{abstract}
:
In the secondary education in many countries of the world, maps are mainly used in geography lessons. Pupils commonly learn how to use maps as a sources of information (they are taught to find relevant information, locate places on the map, decode the language of the map etc.). However, maps do not only provide us with information about where individual cities, mountains or rivers lie. They can also help us analyse and interpret spatial information and derive our decisions from it. Such cognitively demanding map skills (i.e., the map analysis and interpretation) should be of higher attention to the cartographical education as development of these skills can helps teachers to educate competent $21 \mathrm{st}$ century citizens.
\end{abstract}

However, it is crucial to develop cartographic skills systematically and comprehensively. Specifically, teachers and their students should gradually proceed from the cognitively less demanding tasks to the most complex ones particularly from map reading, through analysis to interpretation of maps. And, finally, the results of the interpretation could be visualized in a new map - the map design skills are then developed.

Numerous research studies on cartography education and specifically cartography skills have been carried out in the last decades in Czechia. These studies show that Czech secondary students are fully skilled in map reading, but the map analysis and interpretation skills are rarely sufficiently developed. It is supposed, that the most important causes of this situation are: (a) curriculum oriented on cognitively less demanding skills and (b) teachers and their preferences of development simple map reading to more complex operations with maps. However, there is an deficiency in research focusing on the interactions between student and teacher during the map use in lessons and on teacher's influence during development of students' map skills .

Being aware of these research gaps, following research questions raised: How do teachers use maps in their lessons? What type of maps do they commonly use in lessons? What map skills do teachers dominantly develop in their students? Do teachers develop map skills comprehensively and systematically? What are the most common students' bottlenecks when working with maps?

Considering this, the aim of the proposed paper is to bring insight into map use in lower secondary lessons and provide answers to these questions employing the analysis of 20 videostudies of lessons aimed at map skills development, and, subsequently, the semi-structured interviews with teachers. These interviews focus on the issues related to teachers' personal beliefs and conceptions of cartography education and map skills development in particular. Finally, the findings from videostudies and interviews were confronted to allow unique comparison of theoretical/intended (interview) and practical (real lesson) aspects of cartography education.

The findings mainly show that teachers do not develop map skills comprehensively and focus mainly on reading the map (especially locating objects on maps). However, it is encouraging that most teachers actively use the map in class. Teachers commonly take responsibility for choosing the right map, and students do not practice this skill. The most common bottle-necks in map work, perceived by teachers, is the use of geographical coordinates or time zones. Teachers also think that the development of map skills should start at the youngest possible age, ideally in pre-school education. 